\title{
Practice for preterm patent ductus arteriosus; focusing on the hemodynamic significance and the impact on the neonatal outcomes
}

\author{
Jin A Lee, MD, PhD ${ }^{1,2}$ \\ ${ }^{1}$ Division of Neonatology, Department of Pediatrics, Seoul National University College of Medicine, Seoul, ${ }^{2}$ Division of Neonatology, Department of Pediatrics, Seoul \\ Metropolitan Government - Seoul National University Boramae Medical Center, Seoul, Korea
}

Hemodynamically significant preterm patent ductus arteriosus (PDA) affects mortality; comorbidities such as necrotizing enterocolitis, intraventricular hemorrhage, and bronchopulmonary dysplasia; and adverse long-term neurodevelopmental outcomes in preterm infants, particularly in very low birth weight infants. However, recent studies have indicated that there is no consensus on the causal relationship between PDA and neonatal outcomes, the benefit of PDA treatment, the factors guiding the need for treatment, and optimal treatment strategies. Such uncertainty has resulted in wide variations in practice for treating preterm PDA between units, regions, and nations. Nowadays, there has been a paradigm shift to more conservative treatment for preterm PDA, and suggestions regarding selective management of preterm PDA considering risk factors and hemodynamic significance are increasing. Neonatologist-performed echocardiography and advances in modalities to assess hemodynamic significance such as biologic markers and near-infrared spectroscopy also help improve the efficacy of selective treatment of preterm PDA.

Key words: Patent ductus arteriosus, Premature infant, Therapeutics, Treatment outcome

\section{Introduction}

The ductus arteriosus normally constricts and functionally closes by 72 hours after birth in term infants. However, in preterm infants, particularly those at $<28$ weeks' gestational age (GA), the rate of spontaneous ductal closure decreases, and treatment may be required if patent ductus arteriosus (PDA) shows hemodynamic significance, because PDA affects many comorbidities and the mortality rate in preterm infants, particularly in very low birth weight (VLBW) infants. ${ }^{1-3)}$

However, there are many controversies on the influence of preterm PDA and efficacy of PDA treatment on neonatal outcomes in preterm infants. Here, we review current research data on the definition and influence on neonatal outcomes of hemodynamically significant PDA (hsPDA) and optimal treatment modalities of preterm PDA considering hsPDA.

\section{Natural history of preterm PDA}

Physiologically, the ductus arteriosus should be patent in fetal life to provide oxygensaturated blood from the placenta to the fetus, predominantly via the right-to-left shunt. In most term infants, the ductus arteriosus usually constricts within 72 hours of birth and is functionally followed by anatomical remodeling. ${ }^{4}$ However, in preterm infants, the ductus
Corresponding author: Jin A Lee, MD, PhD

Department of Pediatrics, Seoul Metropolitan Government - Seoul National University Boramae Medical Center, 20, Boramae-ro 5-gil, Dongjak-gu, Seoul 07061, Korea

Tel: +82-2-870-2364

Fax: +82-2-831-2826

E-mail: ljinna@snu.ac.kr

https://orcid.org/0000-0002-9194-0529

Received: 28 October, 2018

Revised: 7 March, 2019

Accepted: 6 April, 2019

\section{Copyright (c) 2019 by The Korean Pediatric Society}

This is an open-access article distributed under the terms of the Creative Commons Attribution NonCommercial License (http://creativecommons.org/ licenses/by-nc/4.0/) which permits unrestricted noncommercial use, distribution, and reproduction in any medium, provided the original work is properly cited. 
arteriosus is still patent after birth, with a failure rate of constriction up to $70 \%$ in infants at $<28$ weeks' $\mathrm{GA}^{5}$ and $80 \%$ at $24-25$ weeks' GA. ${ }^{6}$ When Herrman et al. ${ }^{7)}$ followed VLBW infants who still had preterm PDA after discharge from the neonatal intensive care unit (NICU), almost all had spontaneous PDA closure during early infancy at a median postmenstrual age of 48 weeks.

\section{PDA incidence in VLBW infants in Korea according to the Korean Neonatal Network database}

According to the Korean Neonatal Network (KNN) 2017 annual report, 54.6\% of VLBW infants had no PDA. ${ }^{8)}$ Among VLBW infants registered in the KNN, 1.3\% received prophylactic treatment (treatment before knowing about the presence of PDA), 9.2\% presymptomatic treatment, 21.3\% symptomatic treatment, and 6.1\% conservative treatment. ${ }^{8)}$ Totally, 38.9\% of the total VLBW infants registered in KNN in 2013-2014 received pharmacologic or surgical treatment, $35.5 \%$ received pharmacological treatment, and 12.3\% underwent surgical ligation. ${ }^{9}$

\section{Hemodynamically significant PDA}

HsPDA is usually defined if there is PDA with significant left-toright shunt through the ductus arteriosus, which is confirmed by echocardiography and clinical evidence of systemic hypoperfusion and pulmonary overcirculation. PDA symptoms include hypotension, particularly decreased diastolic blood pressure, characteristic systolic murmur, tachycardia, hyperactive precordium, and wide pulse pressure. Chest radiography reveals increased pulmonary vascularity and left heart dilatation in hsPDA. Although several studies have been conducted on hsPDA worldwide and McNamara and Hellman suggested a PDA staging system using clinical and echocardiographic parameters, the definition of hsPDA even in randomized controlled trials (RCTs) varies widely and lacks consensus. ${ }^{10,11)}$ When combined with echocardiographic parameters, biological markers such as brain natriuretic peptide (BNP) and NTproB-type natriuretic peptide are used to predict hsPDA and the response to pharmacologic treatment. ${ }^{12-17)}$ Recently, near-infrared spectroscopy was used to identify mesenteric hypoperfusion associated with hsPDA; therefore, simultaneously monitoring splanchnic near-infrared spectroscopy and echocardiography can more easily identify hsPDA with ductal steal. ${ }^{18)}$

\section{Echocardiographic assessment}

Among echocardiographic parameters associated with hsPDA prediction, internal PDA diameter is well known for recognizing
hsPDA. ${ }^{19,20)}$ The left atrium-to-aortic root (LA/Ao) ratio is the most frequently used echocardiographic parameter of hsPDA. ${ }^{10)}$ Enddiastolic reversal of blood flow in the aorta, right ventricular systolic pressure, left ventricular end-diastolic diameter, and left pulmonary artery (LPA) diastolic flow velocity are also used as echocardiographic parameters of hsPDA. HsPDA is usually defined by the presence of at least one of the following criteria: internal ductal diameter of $\geq 1.5 \mathrm{~mm}$, LA/Ao ratio between 1.4 and 1.6 in moderate PDA and $>1.6$ in large PDA, and LPA diastolic flow velocity of $>0.25$ $\mathrm{m} / \mathrm{sec}^{21)}$ Neonatologists performing functional echocardiography suggested essential echocardiographic parameters and transductal shunt volumes for each parameter (Table 1). ${ }^{22,23)}$

\section{PDA severity scoring system}

For guidance on the need of PDA treatment, McNamara and Sehgal ${ }^{11)}$ suggested a PDA staging system using clinical and echocardiographic parameters to determine hsPDA magnitude and judge the necessity of treatment. This staging system is generally accepted; many studies are conducted based on it. ${ }^{3)}$ Sehgal et al. ${ }^{24)}$ suggested the PDA severity scoring system at the time of treatment adjudicated by functional echocardiography and proved that a high composite score at the time of treatment correlates with a higher incidence of subsequent chronic lung disease (CLD). ${ }^{24)}$ El-khuffash et al. ${ }^{25)}$ suggested the use of the PDA severity score on day 2 after birth for predicting the later occurrence of CLD/death. The PDA severity score included GA, PDA diameter, left ventricular output, maximum shunt velocity across PDA, and late diastolic velocities using pulsed wave Doppler. Using this score, a cutoff of 5 has sensitivity and specificity of $92 \%$ and 87\%, respectively, for the combined outcome of CLD and death.

\section{PDA treatment modalities}

When deciding whether PDA treatment is needed, we have to consider factors including GA, postnatal age, respiratory support level, existing comorbidities, clinical factors, echocardiographic findings such as ductal diameter and hemodynamic parameters, and cardiac biochemical markers such as BNP. Many neonatologists treat PDA when the benefit of treatment outweighs the risk. However, there are controversies whether PDA affects adverse neonatal outcomes and whether PDA treatment can improve neonatal outcomes considering side effects. Therefore, variation in practice for treating preterm PDA is higher than that for treating other preterm comorbidities. Variations for treating preterm PDA exist between physicians within individual centers, units, and regions. ${ }^{26)}$

The broadly accepted consensus in preterm infants is that treatment is recommended for hsPDA, when clinically and echocar- 
Table 1. Essential echocardiographic requirements for assessing the hemodynamic significance of patent ductus arteriosus and transductal shunt volume

\begin{tabular}{|c|c|c|c|}
\hline \multirow{2}{*}{ Echocardiographic indexes } & \multicolumn{3}{|c|}{ Shunt volume } \\
\hline & Small & Moderate & Large \\
\hline \multicolumn{4}{|l|}{ Patent ductus arteriosus dimension and flow } \\
\hline Diameter (mm) & $<1.5$ & $1.5-2.0$ & $\geq 2.0$ \\
\hline Flow direction (left to right, bidirectional with right to left $\leq$ or $>30 \%$ of the cardiac cycle, right to left) & - & - & - \\
\hline Transductal peak systolic velocity $(\mathrm{m} / \mathrm{sec})$ & $>2.0$ & $1.5-2.0$ & $<1.5$ \\
\hline Transductal systolic-to-diastolic velocity gradient & $<2.0$ & $2.0-4.0$ & $>4.0$ \\
\hline \multicolumn{4}{|l|}{ Pulmonary overcirculation } \\
\hline Left ventricular output (mL/kg/min) & $<200$ & 200-300 & $>300$ \\
\hline \multicolumn{4}{|l|}{ Left heart volume loading: choose one parameter } \\
\hline Left atrium to aortic root ratio, left ventricular end-diastolic diameter (mm) & $<1.5$ & $1.5-2.0$ & $>2.0$ \\
\hline Pulmonary vein d wave velocity (cm/sec) & $<0.3$ & $0.3-0.5$ & $>0.5$ \\
\hline Left pulmonary artery end-diastolic velocity (cm/sec) & $<20$ & $20-50$ & $>50$ \\
\hline \multicolumn{4}{|l|}{ Left side pressure loading: choose one parameter } \\
\hline Mitral valve $\mathrm{E}$ to $\mathrm{A}$ wave ratio & $<1$ & 1 & $>1$ \\
\hline Isovolumic relaxation time (msec) & $>40$ & $30-40$ & $<30$ \\
\hline \multicolumn{4}{|l|}{ Systemic shunt effect } \\
\hline Flow direction in one of the following postductal artery & Antegrade & Absent & Retrograde \\
\hline \multicolumn{4}{|l|}{ Aorta descendant or } \\
\hline \multicolumn{4}{|l|}{ Celiac trunk } \\
\hline Middle cerebral artery (forward, absent, reversed) & & & \\
\hline
\end{tabular}

Modified from de Boode WP, et al., Semin Fetal Neonatal Med 2018;23:292-7, with permission of Elsevier. ${ }^{23)}$

diographically confirmed. Early targeted treatment using echocardiography in the first 72 hours in extremely preterm infants is an interesting treatment option; benefits of early targeted treatment are being tested in large RCTs. ${ }^{27)}$

\section{Pharmacologic treatment}

Cyclooxygenase inhibitor (COXI) therapy is the gold-standard pharmacologic treatment for PDA. In Korea, indomethacin is unavailable now since the supply of medicines from pharmaceutical companies of Korea has been disontinued, so most NICUs use ibuprofen for pharmacologic treatment (up to 95.8\% of infants). ${ }^{8}$ ) According to the $2017 \mathrm{KNN}$ annual report, the drug was intravenously administered in $74.6 \%$ of infants.

According to meta-analyses on the efficacy of ibuprofen and indomethacin, there are no differences in the treatment effect, with relatively less side effects including necrotizing enterocolitis (NEC) and transient renal insufficiency. ${ }^{28)}$ Other meta-analyses on the association of placebo, indomethacin, ibuprofen, and acetaminophen with hsPDA closure suggested that high oral ibuprofen dose (15-20 mg/kg oral followed by 7.5-10 mg/kg oral every $12-24$ hours, 3 doses totally) was associated with a higher likelihood of hsPDA closure. ${ }^{29)}$ However, nephrotoxicity and pulmonary hyper- tension after ibuprofen administration were reported in some units, which are severe side effects. ${ }^{30,31)}$ Hyperbilirubinemia was also associated with ibuprofen use. . $^{32,33)}$

As an alternative to ibuprofen, acetaminophen is considered, however, there is no report about the use of acetaminophen in Korea till now. In some RCTs on the efficacy and safety of oral paracetamol versus oral ibuprofen in hsPDA treatment, oral paracetamol was as effective as ibuprofen for hsPDA closure and was as safe as oral ibuprofen. ${ }^{34-36)}$ According to the Cochrane Database review, paracetamol is as effective as ibuprofen with moderate-quality evidence and paracetamol is more effective than placebo or no intervention with low-quality evidence. There was no difference in neurodevelopmental outcomes between paracetamol and ibuprofen. ${ }^{37)}$ Acetaminophen had relatively less toxicity than ibuprofen and indomethacin. However, acetaminophen hepatotoxicity should not be overlooked during preterm PDA treament. ${ }^{31)}$ Till date, acetaminophen can be considered an optimal substitute to ibuprofen; however, more information is needed on the influence of acetaminophen on preterm infant neurodevelopment.

\section{Surgical treatment}

PDA ligation can be performed when pharmacologic PDA treat- 
ment failed or when there was a contraindication for pharmacologic treatment such as NEC, decreased urine output, or bleeding tendency. However, there were many concerns on the adverse effects of neurodevelopmental outcomes, bronchopulmonary dysplasia (BPD), or retinopathy of prematurity (ROP) of preterm infants. ${ }^{38,39)}$ Weisz et al. ${ }^{40)}$ suggested that when neonatal outcomes of extremely preterm infants with persistent PDA after unsuccessful pharmacologic closure were compared between neonates who underwent surgical ligation and those who did not undergo ligation, there was no association between surgical ligation and the adverse composite outcome of death or neurodevelopmental impairment, neurodevelopmental impairment alone, BPD, or ROP among survivors.

Catheter-based PDA closure even in neonates with $<2 \mathrm{~kg}$ of body weight at the time of the procedure was safe with shorter hospital stays than with surgical ligation. ${ }^{41-44)}$ Catheter-based PDA closure in adults, children, and infants $\geq 6 \mathrm{~kg}$ was the historical treatment of choice, and evidence is increasing on the effectiveness and safety of catheter-based PDA closure in infants with lower weight ( $<6 \mathrm{~kg}$ ). ${ }^{45,46)} \mathrm{Abu}$ Hazeem et al ${ }^{47)}$ reported a faster recovery of respiratory function with percutaneous PDA closure in small infants whose birthweights less than $4 \mathrm{~kg}$ than with surgical ligation.

\section{Conservative treatment}

Considering the possibility of spontaneous PDA closure and iatrogenic adverse effects of PDA treatment in infants at <28 weeks' GA, conservative approaches are being increasingly used, such as positive pressure (e.g., lower inspiratory time and high positive end expiratory pressure) and fluid restriction $(130 \mathrm{~mL} / \mathrm{kg} /$ day after 3 postnatal days). ${ }^{48,49)}$ Even in infants at extremely low GA, such as 24-26 weeks, no intervention was associated with lesser BPD than mandatory closure. ${ }^{50)}$ Placebo or no treatment did not significantly change the likelihood of mortality, NEC, or intraventricular hemorrhage (IVH) when compared with other treatment modalities. ${ }^{29)}$ Although there has been increasing tendency for not treating preterm PDA, the consensus on PDA treatment suggests treating hsPDA rather than not treating it at all.

\section{Prophylactic treatment of preterm PDA}

Till now, there is no clear-cut guideline on the optimal timing of PDA treatment in preterm infants. Options considering the timing of PDA treatment are prophylactic treatment, early targeted/ presymptomatic treatment, late symptomatic treatment, and conservative or no treatment. The TIPP (trial of indomethacin prophylaxis in preterm infants) study showed that the risk of IVH decreased after prophylactic indomethacin treatment. Reports demonstrated that prophylactic indomethacin was effective in reducing hypotension, BPD, and BPD or death by closing PDA. ${ }^{51,52)}$ However, Jensen et al. ${ }^{53)}$ reported that prophylactic indomethacin use varied in hospitals and was not associated with either reduced or increased risk of BPD or death. In a meta-analysis, there was a weak association between indomethacin prophylaxis and decreased mortality odds. ${ }^{54)}$ Till now, there are no reports suggesting the benefit of prophylactic ibuprofen treatment on mortality or neonatal outcomes. ${ }^{55,56)}$

\section{PDA treatment and neonatal outcomes}

According to recent multicenter cohort studies on the treatment policy for preterm PDA, the proportion of preterm infants receiving PDA treatment decreased in VLBW infants, and there was a paradigm shift from treating all preterm infants with PDA to a more conservative approach. ${ }^{57-59)}$ In a large population of infants at $<30$ weeks' GA using the Pediatrix Clinical Data Warehouse in the United States, there were significant decreases PDA diagnosis and treatment from 2006 to $2015{ }^{60)}$ The rationale for this change is due to the observation that active measures to close PDA did not decrease the mortality and major comorbidities in preterm infants ${ }^{61-63)}$ and that spontaneous ductal closure occurred in a substantial portion of infants, particularly in more mature infants, especially in infants with GA > 29 weeks. For long-term neurodevelopmental outcomes, there are reports that PDA presence in moderately preterm, low birthweight infants does not impact long-term neurodevelopmental outcomes. ${ }^{64)}$ Routine prophylactic treatment of PDA on the day of birth is not superior in reducing BPD to delaying treatment by 2-3 days. ${ }^{65)}$ However, early pharmacologic treatment decreased BPD by reducing the moderate-to-large PDA shunt within the first 7-10 days after birth. After the first week, routine pharmacologic treatment seemed to no longer alter the course of BPD development compared with continued PDA exposure. ${ }^{65}$ Contrary to the favorable outcome of the conservative management of preterm PDA, Hagadorn et al. ${ }^{58)}$ found that although the PDA intervention rate fell, the incidence of BPD, periventricular leukomalacia (PVL), ROP, and acute renal failure increased. When researchers assessed the difference in neonatal outcomes between units, the difference in PDA treatment policy was a significant factor for such differences in outcomes. ${ }^{66)}$

PDA ligation, particularly early PDA ligation, was associated with worse neurodevelopmental outcomes. ${ }^{39,67)}$ However, recent studies suggest that the influence of PDA treatment on neonatal outcomes differ according to GA. PDA ligation of preterm infants at $<28$ weeks' GA was not associated with composite outcomes of death or neurodevelopmental impairment. ${ }^{68)}$ PDA treatment with either COXI or ligation was associated with decreased mortality in infants born weighing 400-749 g. ${ }^{66}$ However, some researchers suggest that there was no difference in neonatal outcomes between infants receiving PDA ligation and those not receiving ligation after failure 
Table 2. Resources available for neonatologist-performed echocardiography training

Resources available for neonatologist-performed echocardiography pretraining

-Skinner J, Alvaerson D, Hunter S. Echocardiography for the neonatologist. Edinburgh: Churchill Livingstone, 2001. ISBN-13: 978-0443054808

-Targeted Neonatal Echocardiography: http://www.tnecho.com

-NeonatalEchoSkills: http://www.neonatalechoskills.com

-Practical Ultrasound for the Neonatologist: https://practical-neonatal-ultrasound.selz.com

-https://itunes.apple.com/ie/app/tnecho

of pharmacologic PDA treatment. ${ }^{40)}$ Oral acetaminophen instead of surgical ligation after failure of treatment with indomethacin has been suggested by some neonatologists. ${ }^{69)}$

\section{Early targeted treatment and Neonatologist- performed echocardiography}

Nowadays, many trials are performed on the early prediction of hsPDA and PDA-associated comorbidities, which attempt to assess the beneficial effects of early targeted PDA treatment. ${ }^{27}$ Such targeted treatment is somewhat contrary to the current tendency toward conservative PDA treatment and the efficacy has not been confirmed yet. Recent evidence suggests that no single echocardiographic parameter or clinical marker accurately predicts PDA-related comorbidities including death, IVH, NEC, and BPD. Therefore, the combination of clinical and echocardiographic parameters and serial measurement of such markers are needed to improve the predictability of PDA-related comorbidities. ${ }^{25)} \mathrm{NPE}$ is used to select infants who would potentially benefit from treatment by hemodynamic significance estimation, spontaneous closure prediction, and morbidity risk prediction. ${ }^{23,70)}$ Neonatologists perform echocardiography daily to assess changes in hemodynamics due to PDA and decide when to start pharmacologic treatment and stop before finishing one cycle of ibuprofen or indomethacin treatment, which can reduce drug side effects. Many researchers believe that echocardiographic indicators of hsPDA precede clinical symptoms of PDA by around 2 days. ${ }^{71)}$ The EPIPAGE2 study showed that early screening echocardiography before day 3 of life reduced inhospital mortality and pulmonary hemorrhage; however, it was not associated with differences in NEC, severe BPD, or severe cerebral lesions. ${ }^{72)}$ The European Society for Paediatric Research and European Board of Neonatology prepared the European consensus statement on NPE and developed a special training program divided into basic echocardiography training and advanced echocardiography training (Table 2). There are several valuable resources available on the Internet (Table 2). TnECHO was provided by ElKhuffash and McNamara and provided detailed information on performing echocardiography and obtaining useful parameters to judge the hemodynamic significance of PDA (Table 1). Neonatal echocardiography skills are required to perform echocardiography in neonates; different software for practical echocardiography were introduced by Evans and Malcolm. In Japan, neonatologistperformed functional echocardiography has been conducted daily since the past; in Korea, some neonatologists are performing functional echocardiography these days.

\section{Conclusion}

There is no consensus of PDA effects on neonatal outcomes, treatment efficacy of preterm PDA on neonatal outcomes, and optimal timing and modality of preterm PDA treatment. Threfore, in practice, unit variation of treatment modality for preterm PDA is higher than those for other preterm morbidities. It will be helpful to perform studies knowing about the unit variation of treatment for preterm PDA in Korea using natinoal data such as the KNN database. Knowing about the unit variation in practice about preterm PDA will be also helpful to make a standardized protocol for PDA treatment and start nationwide quiality improvement about preterm PDA treatment. The requirement of NPE to perform targeted treatment of preterm hsPDA in an earlier life is increasing; special training courses on NPE should be provided by the Korean Society of Neonatology in the future.

\section{Conflicts of interest}

No potential conflict of interest relevant to this article was reported.

\section{References}

1. Clyman RI. The role of patent ductus arteriosus and its treatments in the development of bronchopulmonary dysplasia. Semin Perinatol 2013;37:102-7.

2. Noori S, McCoy M, Friedlich P, Bright B, Gottipati V, Seri I, et al. Failure of ductus arteriosus closure is associated with increased mortality in preterm infants. Pediatrics 2009;123:e138-44.

3. Schena F, Francescato G, Cappelleri A, Picciolli I, Mayer A, Mosca F, et al. Association between hemodynamically significant patent ductus arteriosus and bronchopulmonary dysplasia. J Pediatr 2015;166: 1488-92. 
4. Evans NJ, Archer LN. Postnatal circulatory adaptation in healthy term and preterm neonates. Arch Dis Child 1990;65(1 Spec No):24-6.

5. Rolland A, Shankar-Aguilera S, Diomandé D, Zupan-Simunek V, Boileau P. Natural evolution of patent ductus arteriosus in the extremely preterm infant. Arch Dis Child Fetal Neonatal Ed 2015;100: F55-8.

6. Heuchan AM, Clyman RI. Managing the patent ductus arteriosus: current treatment options. Arch Dis Child Fetal Neonatal Ed 2014;99: F431-6.

7. Herrman K, Bose C, Lewis K, Laughon M. Spontaneous closure of the patent ductus arteriosus in very low birth weight infants following discharge from the neonatal unit. Arch Dis Child Fetal Neonatal Ed 2009;94:F48-50.

8. Korea Centers for Disease Control and Prevention. Korean Neonatal Network Annual Report 2017. Cheongju (Korea): Korea Centers for Disease Control and Prevention, 2018.

9. Lee JA, Kim MJ, Oh S, Choi BM. Current status of therapeutic strategies for patent ductus arteriosus in very-low-birth-weight infants in Korea. J Korean Med Sci 2015;30 Suppl 1:S59-66.

10. Zonnenberg I, de Waal K. The definition of a haemodynamic significant duct in randomized controlled trials: a systematic literature review. Acta Paediatr 2012;101:247-51.

11. McNamara PJ, Sehgal A. Towards rational management of the patent ductus arteriosus: the need for disease staging. Arch Dis Child Fetal Neonatal Ed 2007;92:F424-7.

12. Choi BM, Lee KH, Eun BL, Yoo KH, Hong YS, Son CS, et al. Utility of rapid B-type natriuretic peptide assay for diagnosis of symptomatic patent ductus arteriosus in preterm infants. Pediatrics 2005;115:e25561.

13. Shin J, Lee EH, Lee JH, Choi BM, Hong YS. Individualized ibuprofen treatment using serial B-type natriuretic peptide measurement for symptomatic patent ductus arteriosus in very preterm infants. Korean J Pediatr 2017;60:175-80.

14. Hu Y, Jin H, Jiang Y, Du J. Prediction of therapeutic response to cyclooxygenase inhibitors in preterm infants with patent ductus arteriosus. Pediatr Cardiol 2018;39:647-52.

15. Weisz DE, McNamara PJ, El-Khuffash A. Cardiac biomarkers and haemodynamically significant patent ductus arteriosus in preterm infants. Early Hum Dev 2017;105:41-7.

16. Kulkarni M, Gokulakrishnan G, Price J, Fernandes CJ, Leeflang M, Pammi M. Diagnosing significant PDA using natriuretic peptides in preterm neonates: a systematic review. Pediatrics 2015;135:e510-25.

17. Jeong HA, Shin J, Kim E, Lee EH, Choi BM, Son CS, et al. Correlation of B-type natriuretic peptide levels and echocardiographic parameters in preterm infants with patent ductus arteriosus. Korean J Pediatr 2016;59:183-9.

18. Ledo A, Aguar M, Núñez-Ramiro A, Saénz P, Vento M. Abdominal near-infrared spectroscopy detects low mesenteric perfusion early in preterm infants with hemodynamic significant ductus arteriosus. Neonatology 2017;112:238-45.

19. Yum SK, Moon CJ, Youn YA, Lee JY, Sung IK. Echocardiographic assessment of patent ductus arteriosus in very low birthweight infants over time: prospective observational study. J Matern Fetal Neonatal Med 2018;31:164-72.

20. Kluckow M, Evans N. Early echocardiographic prediction of symptomatic patent ductus arteriosus in preterm infants undergoing mechanical ventilation. J Pediatr 1995;127:774-9.

21. Sehgal A, McNamara PJ. Does echocardiography facilitate determination of hemodynamic significance attributable to the ductus arteriosus? Eur J Pediatr 2009;168:907-14.

22. van Laere D, van Overmeire B, Gupta S, El Khuffash A, Savoia M, McNamara PJ, et al. Application of NPE in the assessment of a patent ductus arteriosus. Pediatr Res 2018 ;84(Suppl 1):46-56.

23. de Boode WP, Kluckow M, McNamara PJ, Gupta S. Role of neonatologist-performed echocardiography in the assessment and management of patent ductus arteriosus physiology in the newborn. Semin Fetal Neonatal Med 2018;23:292-7.

24. Sehgal A, Paul E, Menahem S. Functional echocardiography in staging for ductal disease severity : role in predicting outcomes. Eur J Pediatr 2013;172:179-84.

25. El-Khuffash A, James AT, Corcoran JD, Dicker P, Franklin 0, Elsayed YN, et al. A patent ductus arteriosus severity score predicts chronic lung disease or death before discharge. J Pediatr 2015;167:1354-61. e2.

26. Sehgal A, McNamara PJ. International perspective on management of a patent ductus arteriosus: Lessons learned. Semin Fetal Neonatal Med 2018;23:278-84.

27. Wyllie JP, Gupta S. Prophylactic and early targeted treatment of patent ductus arteriosus. Semin Fetal Neonatal Med 2018;23:250-4.

28. Ohlsson A, Walia R, Shah SS. Ibuprofen for the treatment of patent ductus arteriosus in preterm or low birth weight (or both) infants. Cochrane Database Syst Rev 2018;9:CD003481.

29. Mitra S, Florez ID, Tamayo ME, Mbuagbaw L, Vanniyasingam T, Veroniki AA, et al. Association of placebo, indomethacin, ibuprofen, and acetaminophen with closure of hemodynamically significant patent ductus arteriosus in preterm infants: a systematic review and meta-analysis. JAMA 2018;319:1221-38.

30. Amendolia B, Lynn M, Bhat V, Ritz SB, Aghai ZH. Severe pulmonary hypertension with therapeutic L-lysine ibuprofen in 2 preterm neonates. Pediatrics 2012;129:e1360-3.

31. Cuzzolin L, Bardanzellu F, Fanos V. The dark side of ibuprofen in the treatment of patent ductus arteriosus: could paracetamol be the solution? Expert Opin Drug Metab Toxicol 2018;14:855-68.

32. Zecca E, Romagnoli C, De Carolis MP, Costa S, Marra R, De Luca D. et al. Does Ibuprofen increase neonatal hyperbilirubinemia? Pediatrics 2009;124:480-4.

33. Rheinlaender C, Helfenstein D, Walch E, Berns M, Obladen M, Koehne P. Total serum bilirubin levels during cyclooxygenase inhibitor treatment for patent ductus arteriosus in preterm infants. Acta Paediatr 2009;98:36-42.

34. El-Farrash RA, El Shimy MS, El-Sakka AS, Ahmed MG, Abdel-Moez DG. Efficacy and safety of oral paracetamol versus oral ibuprofen for closure of patent ductus arteriosus in preterm infants: a randomized controlled trial. J Matern Fetal Neonatal Med 2018 May 9:1-8. https:// doi.org/10.1080/14767058.2018.1470235. [Epub]

35. Dang D, Wang D, Zhang C, Zhou W, Zhou Q, Wu H. Comparison of oral paracetamol versus ibuprofen in premature infants with patent ductus arteriosus: a randomized controlled trial. PLoS One 2013;8: e77888.

36. Oncel MY, Yurttutan S, Erdeve O, Uras N, Altug N, Oguz SS, et al. Oral paracetamol versus oral ibuprofen in the management of patent ductus arteriosus in preterm infants: a randomized controlled trial. J Pediatr 2014;164:510-4.e1.

37. Ohlsson A, Shah PS. Paracetamol (acetaminophen) for patent ductus arteriosus in preterm or low birth weight infants. Cochrane Database Syst Rev 2018;4:CD010061.

38. Mirea L, Sankaran K, Seshia M, Ohlsson A, Allen AC, Aziz K, et al. Treatment of patent ductus arteriosus and neonatal mortality/morbidities: adjustment for treatment selection bias. J Pediatr 2012;161: 689-94.e1.

39. Bourgoin L, Cipierre C, Hauet Q, Basset H, Gournay V, Rozé JC, et al. Neurodevelopmental outcome at 2 years of age according to patent ductus arteriosus management in very preterm infants. Neonatology 2016;109:139-46. 
40. Weisz DE, Mirea L, Resende MHF, Ly L, Church PT, Kelly E, et al. Outcomes of surgical ligation after unsuccessful pharmacotherapy for patent ductus arteriosus in neonates born extremely preterm. J Pediatr 2018;195:292-6.e3.

41. Pamukcu 0, Tuncay A, Narin N, Baykan A, Korkmaz L, Argun M, et al. Patent ductus arteriosus closure in preterms less than $2 \mathrm{~kg}$ : surgery versus transcatheter. Int J Cardiol 2018;250:110-5.

42. Morville P, Akhavi A. Transcatheter closure of hemodynamic significant patent ductus arteriosus in 32 premature infants by amplatzer ductal occluder additional size-ADOIIAS. Catheter Cardiovasc Interv 2017;90:612-7.

43. Morville P, Douchin S, Bouvaist H, Dauphin C. Transcatheter occlusion of the patent ductus arteriosus in premature infants weighing less than 1200g. Arch Dis Child Fetal Neonatal Ed 2018;103:F198-201.

44. Garg G, Garg V, Prakash A. Percutaneous closure of a large patent ductus arteriosus in a preterm newborn weighing $1400 \mathrm{~g}$ without using arterial sheath: an innovative technique. Cardiol Young 2018; 28:494-7.

45. Pavlek LR, Slaughter JL, Berman DP, Backes CH. Catheter-based closure of the patent ductus arteriosus in lower weight infants. Semin Perinatol 2018;42:262-8.

46. Backes CH, Cheatham SL, Deyo GM, Leopold S, Ball MK, Smith CV, et al. Percutaneous patent ductus arteriosus (PDA) closure in very preterm infants: feasibility and complications. J Am Heart Assoc 2016 Feb 12;5(2). pii: e002923. https://doi.org/10.1161/JAHA.115.002923.

47. Abu Hazeem AA, Gillespie MJ, Thun H, Munson D, Schwartz MC, Dori Y, et al. Percutaneous closure of patent ductus arteriosus in small infants with significant lung disease may offer faster recovery of respiratory function when compared to surgical ligation. Catheter Cardiovasc Interv 2013;82:526-33.

48. Semberova J, Sirc J, Miletin J, Kucera J, Berka I, Sebkova S, et al. Spontaneous closure of patent ductus arteriosus in infants $\leq 1500 \mathrm{~g}$. Pediatrics 2017 Aug;140(2). pii: e20164258. https://doi.org/10.1542/ peds.2016-4258. Epub 2017 Jul 12.

49. Letshwiti JB, Semberova J, Pichova K, Dempsey EM, Franklin OM, Miletin J. A conservative treatment of patent ductus arteriosus in very low birth weight infants. Early Hum Dev 2017;104:45-9.

50. Sung SI, Chang YS, Chun JY, Yoon SA, Yoo HS, Ahn SY, et al. Mandatory closure versus nonintervention for patent ductus arteriosus in very preterm infants. J Pediatr 2016;177:66-71.e1.

51. Liebowitz M, Koo J, Wickremasinghe A, Allen IE, Clyman RI. Effects of prophylactic indomethacin on vasopressor-dependent hypotension in extremely preterm infants. J Pediatr 2017;182:21-7.e2.

52. Liebowitz M, Clyman RI. Prophylactic indomethacin compared with delayed conservative management of the patent ductus arteriosus in extremely preterm infants: effects on neonatal outcomes. J Pediatr 2017;187:119-26.e1.

53. Jensen EA, Dysart KC, Gantz MG, Carper B, Higgins RD, Keszler M, et al. Association between use of prophylactic indomethacin and the risk for bronchopulmonary dysplasia in extremely preterm infants. J Pediatr 2017;186:34-40.e2.

54. Jensen EA, Foglia EE, Schmidt B. Association between prophylactic indomethacin and death or bronchopulmonary dysplasia: a systematic review and meta-analysis of observational studies. Semin Perinatol 2018;42:228-34.

55. Ding Y, Wang X, Wu Y, Li H, Xu J, Wang X. Effects of prophylactic oral ibuprofen on the closure rate of patent ductus arteriosus in premature infants. Medicine (Baltimore) 2018;97:e12206.

56. Ohlsson A, Shah SS. Ibuprofen for the prevention of patent ductus arteriosus in preterm and/or low birth weight infants. Cochrane
Database Syst Rev 2011;(7):CD004213.

57. Lokku A, Mirea L, Lee SK, Shah PS; Canadian Neonatal Network. Trends and outcomes of patent ductus arteriosus treatment in very preterm infants in Canada. Am J Perinatol 2017;34:441-50.

58. Hagadorn J, Brownell EA, Trzaski JM, Johnson KR, Lainwala S, Campbell BT, et al. Trends and variation in management and outcomes of very low-birth-weight infants with patent ductus arteriosus. Pediatr Res 2016;80:785-92.

59. Ngo S, Profit J, Gould JB, Lee HC. Trends in patent ductus arteriosus diagnosis and management for very low birth weight infants. Pediatrics 2017 Apr;139(4). pii: e20162390. https://doi.org/10.1542/peds. 2016-2390.

60. Bixler GM, Powers GC, Clark RH, Walker MW, Tolia VN. Changes in the diagnosis and management of patent ductus arteriosus from 2006 to 2015 in United States neonatal intensive care units. J Pediatr 2017;189:105-12.

61. Chock VY, Goel VV, Palma JP, Luh TM, Wang NA, Gaskari S, et al. Changing management of the patent ductus arteriosus: effect on neonatal outcomes and resource utilization. Am J Perinatol 2017;34: 990-5.

62. Benitz WE, Bhombal S. The use of non-steroidal anti-inflammatory drugs for patent ductus arteriosus closure in preterm infants. Semin Fetal Neonatal Med 2017;22:302-7.

63. Ezenwa B, Pena E, Schlegel A, Bapat R, Shepherd EG, Nelin LD. Effects of practice change on outcomes of extremely preterm infants with patent ductus arteriosus. Acta Paediatr 2019;108:88-93.

64. Collins RT 2nd, Lyle RE, Rettiganti M, Gossett JM, Robbins JM, Casey PH. Long-term neurodevelopment of low-birthweight, preterm infants with patent ductus arteriosus. J Pediatr 2018;203:170-6.e1.

65. Clyman RI. Patent ductus arteriosus, its treatments, and the risks of pulmonary morbidity. Semin Perinatol 2018;42:235-42.

66. Hagadorn JI, Bennett MV, Brownell EA, Payton KSE, Benitz WE, Lee HC. Covariation of neonatal intensive care unit-level patent ductus arteriosus management and in-neonatal intensive care unit outcomes following preterm birth. J Pediatr 2018;203:225-33.e1.

67. Jhaveri N, Moon-Grady A, Clyman RI. Early surgical ligation versus a conservative approach for management of patent ductus arteriosus that fails to close after indomethacin treatment. J Pediatr 2010;157: 381-7, 387.e1.

68. Weisz DE, Mirea L, Rosenberg E, Jang M, Ly L, Church PT, et al. Association of patent ductus arteriosus ligation with death or neurodevelopmental impairment among extremely preterm infants. JAMA Pediatr 2017;171:443-9.

69. Mashally S, Nield LE, McNamara PJ, Martins FF, El-Khuffash A, Jain A, et al. Late oral acetaminophen versus immediate surgical ligation in preterm infants with persistent large patent ductus arteriosus. J Thorac Cardiovasc Surg 2018;156:1937-44.

70. de Boode WP, Singh Y, Gupta S, Austin T, Bohlin K, Dempsey E, et al. Recommendations for neonatologist performed echocardiography in Europe: Consensus Statement endorsed by European Society for Paediatric Research (ESPR) and European Society for Neonatology (ESN). Pediatr Res 2016;80:465-71.

71. O'Rourke DJ, El-Khuffash A, Moody C, Walsh K, Molloy EJ. Patent ductus arteriosus evaluation by serial echocardiography in preterm infants. Acta Paediatr 2008;97:574-8.

72. Rozé JC, Cambonie G, Marchand-Martin L, Gournay V, Durrmeyer X, Durox M, et al. Association between early screening for patent ductus arteriosus and in-hospital mortality among extremely preterm infants. JAMA 2015;313:2441-8. 